\title{
Evaluation of Cyclic Durability in Surface- modified Layers with TiNiZr Thermoelastic Phase Transformations
}

\author{
Peter Rusinov ${ }^{*}$, and Zhesfina Blednova ${ }^{1}$ \\ ${ }^{1}$ Kuban State Technological University, Engineering and Service Centers, Dynamics and Strength \\ of Machines, Moskovskaya 2, Krasnodar, Russia
}

\begin{abstract}
This paper estimated longevity and damaging of surface materials modified by alloys with thermoelastic phase transformations, taking into account: the energy consumed for the formation of failure micro-surface in one cycle, in terms of the shape of the hysteresis loop; energy intensity of the alloy, in the light of phase composition by the results of X-ray diffraction analysis. The energy intensity and theoretical strength of ternary TiNiZr systems are calculated and plotted according to thermodynamic characteristics and phase diagrams of ternary systems. This paper carried out tests of steels with surface-modified TiNiZr layers under conditions of multicyclic fatigue and frictional friction.
\end{abstract}

\section{Introduction}

Two approaches are used to describe phenomena occurring in alloys with thermoelastic phase transformations: a straight one, when the system evolution laws are described by the consideration of transformation micromechanisms [1,2], or directly through experiments [3]; a thermodynamic one, which is based on the analysis of the free system energy and includes the state variables that allow determining the volume fractions of various martensite forms [4]. To develop a methodology for predicting the fatigue strength of cyclic durability, the universal approaches applicable to complex systems, including statistical ones, energy (thermodynamic) and synergistic ones, can be considered as a theoretical basis. For surface-hardened materials or composite surface-modified materials, the most suitable is the energy (thermodynamic) approach, based on the analogy of the destruction, plastic deformation and melting, and the fractal-synergetic approach associated with it. The choice of the energy criterion based on the analogy of deformation, fracture and melting, evaluation of the cyclic durability of surface-modified materials is explained by the following fact: energy (energy intensity, energy content) is an additive quantity and can be determined for multicomponent materials, taking into account the chemical composition of the surface layer responsible for the destruction. It also can be determined by thermodynamic characteristics and phase diagrams of systems. Energy intensity can be

\footnotetext{
*Corresponding author: ruspiter5@mail.ru
} 
determined taking into account the technological operations of surface modification based on the results of X-ray diffraction analysis.

The purpose of this paper is to estimate the cyclic durability in surface-modified layers with thermoelastic phase transformations of TiNiZr.

To evaluate longevity, we proposed a version of the energy model of damage accumulation in a surface-doped material for two component alloys, proposed by the following authors $[5,6]$. Models $[5,6]$ consist in the fact that for the destruction of material it is necessary to spend part of the magnitude of the irreversible deformation work. The accumulation of damage consumes not all, but only a fraction of the irreversible deformation work. In order to establish this fraction which depends on the conditions of heat exchange, on the degree of deformation, etc., it is necessary to refer to a physical or mechanical experiment.

The energy consumed on the distortion of the crystal lattice is determined by the formula [6]:

$$
H=\int_{T}^{T_{m}} c_{p} \cdot d T
$$

Where $\mathrm{c}_{\mathrm{p}}$ - specific heat, $\mathrm{J} / \mathrm{kg} \cdot \mathrm{K}$;

$\mathrm{T}$ - temperature, $\mathrm{K}$;

$\mathrm{T}_{\mathrm{m}}$ - melting point, $\mathrm{K}$.

The ultimate energy (energy intensity) absorbed by the body at the temperature $\mathrm{T}$ at its melting is determined by the formula:

$$
\mathrm{Q}=\int_{\mathrm{T}}^{\mathrm{T}_{\mathrm{m}}} \mathrm{c}_{\mathrm{p}} \cdot \mathrm{dT}+\mathrm{Lm}
$$

Where Lm - latent heat of melting.

The theoretical strength is determined by the formula [6]:

$$
\sigma_{\text {теор }}=\sqrt{\mathrm{E} \cdot \mathrm{Q}}
$$

Where E - the Young's modulus, MPa.

The latent heat of melting is determined from the formula [6]:

$$
\mathrm{L}_{\mathrm{m}}=\Delta \mathrm{S}_{\mathrm{m}} \cdot \mathrm{T}_{\mathrm{m}}
$$

Where $\Delta \mathrm{Sm}$ - the change in the body entropy during its melting.

The entropy of melting is found from the formula [6]:

$$
\Delta \mathrm{Sm}=\mathrm{A}_{1} \cdot \Delta \mathrm{S}^{1}+\mathrm{A}_{2} \cdot \Delta \mathrm{S}^{2}
$$

According to the Neumann-Conne formula, the heat capacity of an alloy is calculated from the formula [6]:

$$
\mathrm{c}_{\mathrm{p}}^{\mathrm{m}}=\mathrm{A}_{1} \cdot \mathrm{c}_{\mathrm{p}}{ }^{1}+\mathrm{A}_{2} \cdot \mathrm{c}_{\mathrm{p}}{ }^{2}
$$

Where $\mathrm{c}_{\mathrm{p}}{ }^{1}$ and $\mathrm{c}_{\mathrm{p}}{ }^{2}$ - the specific heat capacities of the alloy components.

In the present work, we calculated the energy capacity and theoretical strength of a multicomponent material with thermoelastic phase transformations of TiNiZr obtained by 
high-velocity oxygen-fuel spraying in a protective atmosphere (argon medium). The entropy and heat capacity were calculated for each of the phases (Fig. 1), comprising the composite layer TiNiZr, according to formulas (5) and (6). Further calculations were made using formulas (1), (2), (3), (4).

The X-ray phase analysis showed that at room temperature the initial phase state of the TiNiZr layer after the high-velocity oxygen-fuel spraying of mechanically activated powder is martensite B19phases with a monoclinic lattice, austenitic B2 phases with a cubic lattice, intermetallide phases $\mathrm{Ni} 3 \mathrm{Ti}, \mathrm{Ti} 2 \mathrm{Ni}, \mathrm{NiZr}, \mathrm{NiZr} 2$, with cubic and hexagonal lattices, and we also observed a small amount of titanium oxide (TiO) - less than $2 \%$ (Fig. 1).

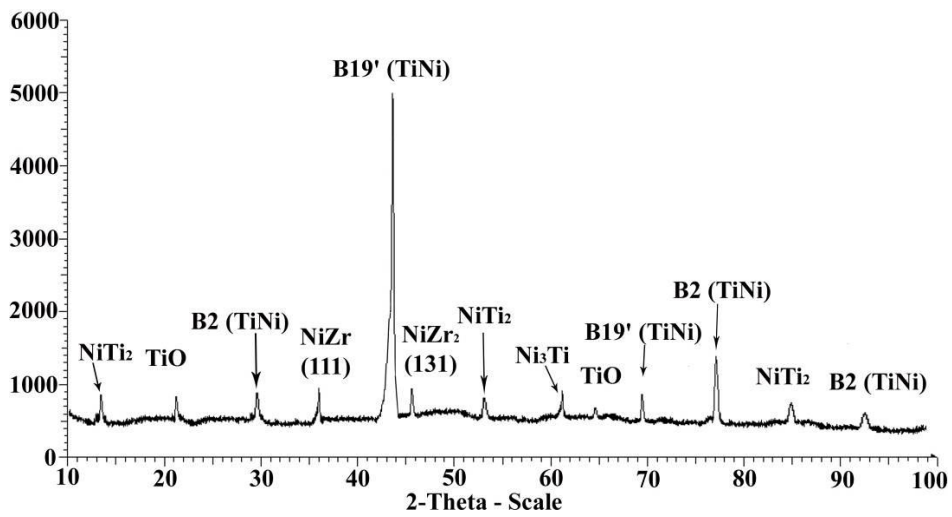

Fig. 1. X-ray phase analysis of TiNiZr alloy, after high-velocity oxygen-fuel spraying with local protection in argon.

For the phases $\mathrm{TiNi}, \mathrm{Ni} 3 \mathrm{Ti}, \mathrm{Ti} 2 \mathrm{Ni}, \mathrm{NiZr}, \mathrm{NiZr} 2, \mathrm{TiO}$ we calculated energy $\mathrm{H}$, spent on the distortion of the crystal lattice, ultimate energy $\mathrm{Q}$ absorbed by the body at the temperature $\mathrm{T}$ during its melting, theoretical strength $\sigma_{\text {theor. }}$ Thus, the energy $\mathrm{H}$ consumed on the distortion of the crystal lattice of the TiNi phase is $36.4 \mathrm{MJ} / \mathrm{kg}$; ultimate energy Q absorbed by the body is $41.14 \mathrm{MJ} / \mathrm{mol}$; theoretical strength of $\sigma_{\text {theor }}$ is $17.91 \mathrm{GPa}$.

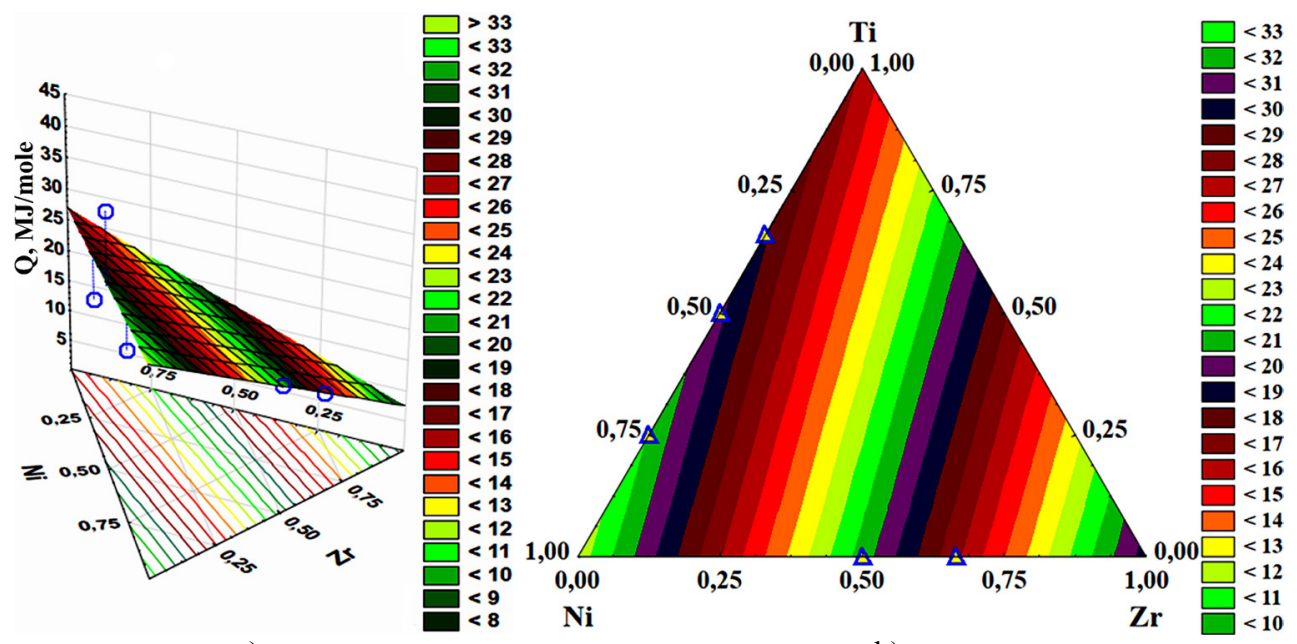

a)

b)

Fig. 2. Energy intensity of Ti-Ni-Zr systems: three-dimensional (a) and two-dimensional model (b).

The calculated values of $\mathrm{H}, \mathrm{Q}$, and $\sigma_{\text {theor }}$ were determined for all the component phases and the following equations were compiled on the basis of statistical processing: 
- ultimate energy Q absorbed by the body at the temperature $\mathrm{T}$ at its melting

$$
\mathrm{Q}=33,5843 \cdot \mathrm{Ni}+7,5379 \cdot \mathrm{Zr}+26,8976 \cdot \mathrm{Ti}(\mathrm{MJ} / \mathrm{mole})
$$

- theoretical strength $\sigma_{\text {theor }}$ is described by equations

$$
\sigma_{\text {theor }}=5,5822+1,0229 \cdot \mathrm{Q}-0,8216 \cdot \mathrm{H}
$$

Where Ni, Zr, Ti - the percentage of elements TiNiHf (at.\%).

Fig. 2 shows the energy capacity of Ti-Ni-Zr alloys (a, b). From Fig. 2 we can see that the energy intensity for the alloy of the Ti-Ni-Zr system is slightly different from the energy capacity of other compounds of this system.

Fig. 3 presents models for calculating the theoretical strength of an alloy of the Ti-Ni-Zr system.

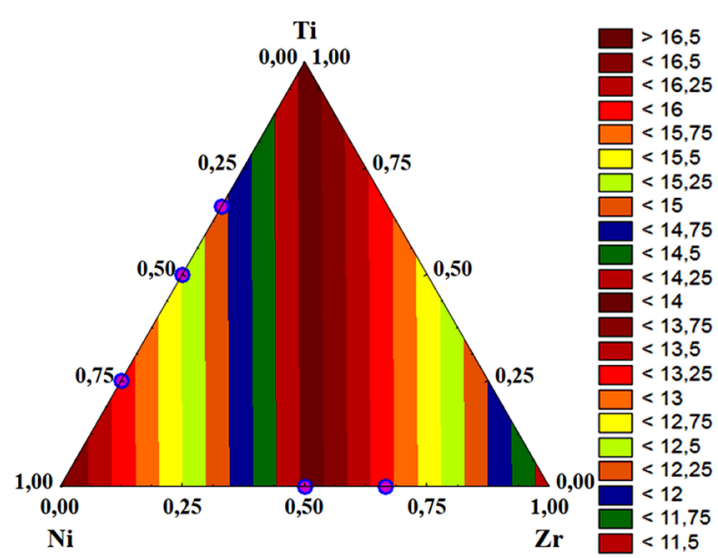

a)

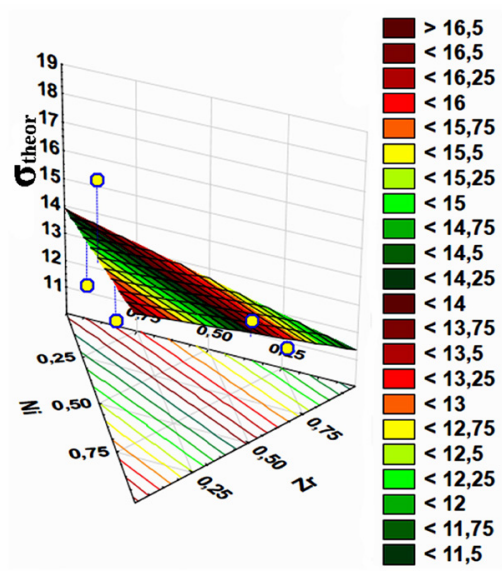

b)

Fig. 3. Theoretical strength of Ti-Ni-Zr systems: two-dimensional (a) and three-dimensional model (b).

\section{Operational properties of surface-modified TiNiZr layers}

As we can see from the samples' tests (steel $1045+$ TiNiZr layer) on multicyclic fatigue with bending at rotation showed, the durability increases (Fig. 4a). The endurance limit $\left(\sigma_{-1}\right)$ of uncoated steel 1045 was $275 \mathrm{MPa}$, and after surface modification with a TiNiZr memory alloy it was $430 \mathrm{MPa}$ (increased by $36 \%$ ). In the process of testing for wear of samples with a surface layer of TiNiZr, an increase in the surface temperature in the friction zone is observed, which causes a martensitic-austenite transformation. Sufficiently large pressures arising from friction cause the plasticity of the transformation effect due to the formation of martensite stress. The combination of these processes determines the wear resistance of the sample. Experience shows that the higher the reversible deformations, the higher the wear resistance is. The increase in wear resistance of steel 1045 with a surface layer of $\mathrm{TiNiZr}$ after HVOF + Thermomechanical treatment is 3.5-3.6 times compared to that of steel 1045 (Fig. 4, b). 


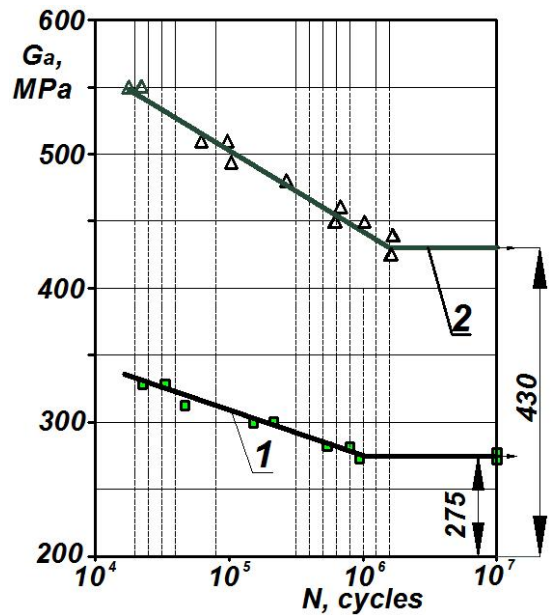

a)

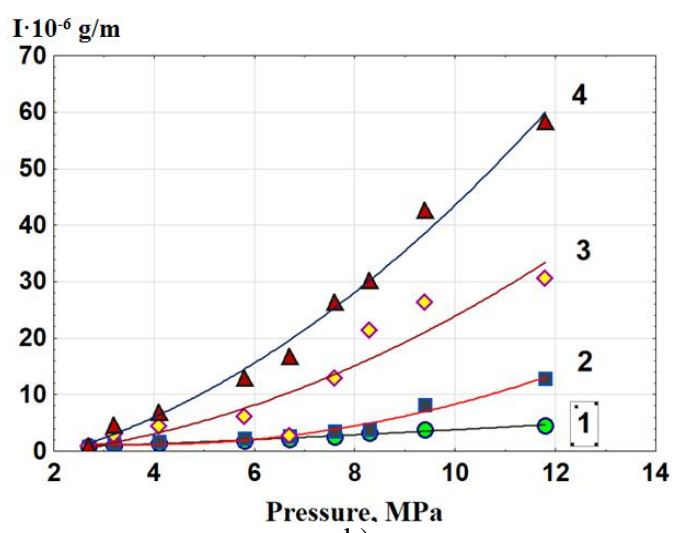

b)

Fig. 4. Curves of the multi-cycle fatigue of steel 1045: uncoated (1), after surface modification with a memory alloy of the form TiNiZr (2) - a); The dependence of the wear rate of the layer I of TiNiZr on the pressure of the disk $P$ at a disk sliding speed of $0.5 \mathrm{~m} / \mathrm{s}-1 ; 1 \mathrm{~m} / \mathrm{s}-2 ; 1.5 \mathrm{~m} / \mathrm{s}-3 ; 2 \mathrm{~m} / \mathrm{s}-4-\mathrm{b}$ ).

The increase in the durability of samples with a nanostructured TiNiZr surface layer is explained both by the features of nanostructured materials destruction consisting in inhibition of fracture at the grain boundaries, preventing branching and movement of cracks due to hardening of the boundaries, as well as by the pseudoelasticity of the TiNiZr surface layer inherent to materials with thermoelastic phase transformations. The deformation accumulated by the surface layer is able to recover during cyclic unloading and, therefore, does not accumulate in the material, which increases its durability.

\section{Summary}

This paper developed an energy criterion for estimating the longevity and damaging of materials, which have been surface-modified by alloys with thermoelastic phase transformations, which takes into account: the energy consumed for the formation of the failure micro-surface in one cycle, in the light of the shape of the hysteresis loop; energy intensity of the alloy, in terms of phase composition according to the results of X-ray diffraction analysis; structural factor of the alloy, which is the coefficient of thermomechanical activity, determined on the basis of fractal-synergetic approach based on the results of multifractal parameterization of the structure and taking into account the influence of fractal dimension, homogeneity, periodicity and structure adaptability; calculations and diagrams of the energy capacity and theoretical strength of the TiNiZr ternary systems based on thermodynamic characteristics and phase diagrams of ternary systems.

After high-velocity oxygen-fuel spraying in the protective atmosphere of a mechanically activated TiNiZr-based shape memory powder, the cyclic durability in conditions of multicyclic fatigue increases by $\sim 36 \%$, and wear resistance is 3.5-3.6 times compared to that of steel 1045 .

This work was supported by a grant from the Russian Science Foundation No. 15-19-00202 and a grant from the President MK-5445.2016.8. 


\section{References}

1. K. Tanaka, S. Nagaki, Ingenieur-Archiv, 51, 13, (1982)

2. K. Tanaka, Res. Mech, 18, (1986)

3. C. Liang, C.J. Rogers, Eng. Math, 26, (1992)

4. D.C. Lagoudas, Z. Bo, M.A. Qidwai, Mech. Composite Mater. Struct., 3, (1996)

5. Zh.M. Blednova, Factory laboratory, 7, (1988)

6. Zh.M. Blednova, The Author's abstract of the thesis of a Dr.Sci.Tech. (1989) 